\title{
Single stage cochlear implantation in radical mastoid cavity- a surgical dilemma
}

\begin{abstract}
Objective: To describe the potential problems of cochlear implantation in mastoid cavity with possibilities of extrusion of electrode array by breakdown of epithelial lining or flap cover recurrent cholesteatoma and spread of infection to the implant. The issues with surgical management and subsequent follow up is discussed.
\end{abstract}

Methods: In a Series of 170 Cochlear Implantations at our centre, four patients had Cochlear Implantation with Blind sac closure, complete removal of epithelium from the radical mastoid cavity, obliteration of the cavity with temporoparietal fascia flap and electrode insertion. Follow up ranging from 21 months up to 84 months is available. One patient during follow up had to undergo re implantation due to extrusion of the electrodes.

Results: All the patients had good outcome regarding hearing improvement. One of the patients had to undergo exploration and re implantation of electrodes due to extrusion of electrodes through the external auditory canal. This patient had a canal cholesteatoma.

Discussion: An important issue in single stage procedure is ensuring complete removal of fibro epithelial lining of the cavity. The advantage is cost reduction and minimizes the need for multiple general anesthesia. A follow up CT scan at regular intervals is required to detect recurrence.

Conclusions: The patients undergoing cochlear implantation in a radical mastoid cavity require intensive follow up with computerized tomography to detect recidivism, Single stage cochlear implantation in radical mastoid cavity is an appropriate therapeutic decision by the cochlear implant surgeon.

Keywords: electrode array, cholesteatoma, mastoid cavity
Volume 12 Issue 3 - 2020

\author{
Naresh K Panda, Gyanaranjan Nayak, Roshan \\ Verma \\ Department of Otolaryngology, Head and Neck Surgery, India
}

Correspondence: Naresh Panda, Department of Otolaryngology, Head and Neck Surgery, PGIMER, Chandigarh, India, Email npanda9@yahoo.co.in

Received: June 15, 2020 | Published: June 23, 2020

\section{Introduction}

Chronic otitis media squamous type is a common otological disease in our country. Many of the patients require mastoidectomy to alleviate their symptoms. A proportion of patients undergoing radical mastoidectomy may develop profound sensorineural loss. Chronic Otitis media could lead to cochlear damage due to several mechanisms.eg bacterial endotoxins or exotoxins. ${ }^{1-3}$ Meningitis due to chronic otitis media may lead to profound sensorineural loss. It can lead to cochlear ossification making cochlear implantation more challenging. Moreover, surgery for chronic otits media could lead to profound sensorineural loss in approximately 3-5\% causes. ${ }^{4}$ Though there is risk of introduction of infection by inserting an electrode through a potentially infected field, it is the only viable option available with the surgical team. The patients with bilateral mastoid cavity with profound sensorineural loss represent a group where the cochlear implant surgeon faces a dilemma. The potential problems could be extrusion of electrode array by breakdown of epithelial lining or flap cover, recurrent cholesteatoma and spread of infection through the implant with possibility of labyrinthitis and meningitis. This paper highlights our experience with cochlear implantation in the presence of mastoid cavity along with the challenges and complications encountered.

\section{Material and methods}

The clinical files of all 170 consecutive patients who had undergone cochlear implantation between April 2004 and June 2018 were retrospectively reviewed in this tertiary care teaching hospital. , The clinical charts of the patients were reviewed for medical history, etiology, electrode insertion, type of implant, surgical management and post operative outcomes including complications. Of these, 4 patients were found to have profound hearing loss along with a radical mastoid cavity. These patients had mastoidectomy in the past and had absolutely dry and epithelized cavity at the time of presentation. The preoperative evaluation included an otolaryngologic examination, complete audiological and radiological evaluation. The radiological investigation included a computerized tomography in both axial and coronal planes and Magnetic resonance imaging. All the patients received Nucleus 24 straight array (Cochlear Corporation). The patients were advised follow up examination every 6 months or earlier if they had symptoms of heaviness in the ear, pain, headache or fever of unexplained cause. .

\section{Surgical management}

All the patients had a single staged cochlear implantation comprising of blind sac closure of external auditory canal Figure 1 complete removal of epithelium from the mastoid cavity, electrode insertion by a standard technique and obliteration of the cavity with temporoparietal fascia flap. A dry epithelized mastoid cavity without any squamous debris is one of the important preoperative pre requisites. The surgical procedure consisted of a post aural incision measuring $4.5 \mathrm{cms}$ which extends superiorly over the scalp for harnessing the temporoparietal fascia flap later. An anterior based Palva flap is raised which would cover the temporoparietal fascia flap 
. A blind sac closure of external; auditory canal is performed at this stage. The blind sac closure was done by the technique described by Meyerhoff et al. ${ }^{5}$

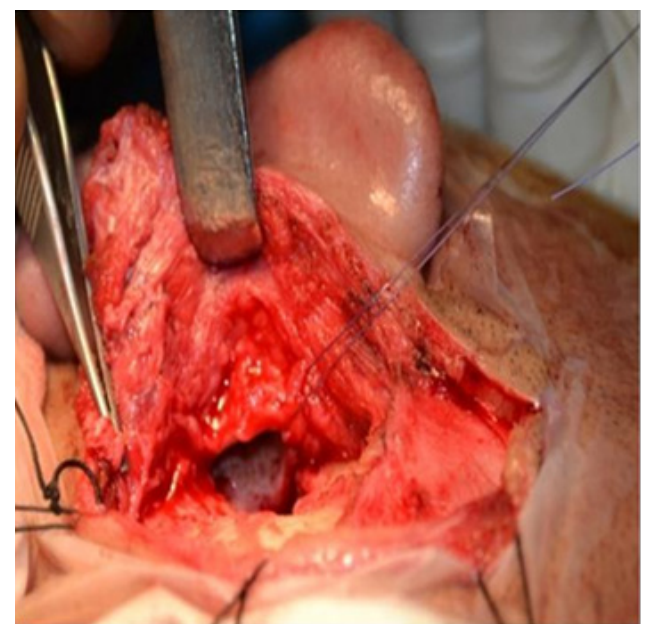

Figure I Showing the blind sac closure of external auditory canal.

After this a temporoparietal fascia flap is elevated in the sub follicular plane of the skin. This flap is based on the anterior branch of superficial temporal artery (Figure 2).

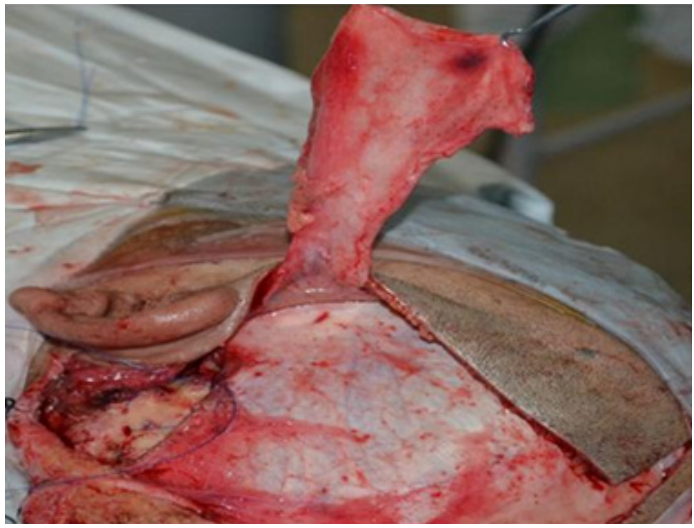

Figure 2 Showing the raised temporo parietal fascia flap.

\section{Mastoid cavity revision}

The mastoid cavity is laid bare of all the epithelial lining along with the middle ear mucosa. The Eustachian tube is closed with a piece of cartilage and perichondrium.

\section{Bed for the receiver stimulator unit}

The bed for the receiver stimulator unit was drilled more posteriorly than in standard procedures. Ideally the distance between the posterior margin of the mastoid cavity and bed for the receiver stimulator unit varied from 2-3 cms. The cochleostomy was performed through the extended round window approach in 2 patients and standard promontory cochleostomy in 1 patient. After inserting the electrodes the cochleostomy was closed with a small piece of fascia... The electrode array was protected by the vascularised temporoparietal fascia flap.

\section{Results}

Of the 170 patients who underwent cochlear implantation at our centre, 4 patients were identified with having radical mastoid cavity. There were 3 males and 1 female in the study group. All of them were adult post lingual patients. All the patients had bilateral radical mastoid cavities secondary to chronic otitis media squamous type. The age ranged from 18 to 50 years with a mean of 32 years. The follow up ranged from a period of 21 months to 84 months. The Cochlear implantation was uneventful in all the patients. All of them had good recovery in the postoperative period. All the 4 patients have been doing well with optimum hearing. They had satisfactory mean bisyllabic word and sentence recognition scores. The detailed profile of the patients is shown in Table 1 .

\section{Complications}

One of the 4 patients during the follow up examination at 21 months was found to have the exposure of the electrodes visible through the external auditory canal. Apparently the blind sac closure had given away. A transorbital X ray done on the same day showed the electrode having come out of the cochlea (Figure 3). He was planned for a re exploration the next day. Exploration showed the mastoid cavity to be absolutely normal, However there was evidence of the presence of cholesteatoma in the external auditory canal alone. There was no evidence of cholesteatoma in rest of the mastoid cavity (Figure 4). The cholesteatoma was removed and the electrode reinserted. The blind sac closure was revised again The post operative $\mathrm{x}$ ray done one day later showed the electrodes in place (Figure 5). A computerized scan done 3 months later showed proper placement of the electrodes with no evidence of any soft tissue in the cavity.

Table I The detailed profile of the four patients

\begin{tabular}{|c|c|c|c|c|c|}
\hline SNo & $\begin{array}{l}\text { Patient's Name } \\
\text { with age }\end{array}$ & DOS & Clinical Presentation & Surgery done & $\begin{array}{l}\text { Outcome with complications } \\
\text { if any }\end{array}$ \\
\hline I. & PS $56 \mathrm{~F}$ & 28.2.20II & $\begin{array}{l}\text { Bilateral mastoid cavities Dry Epithelized } \\
\text { with profound loss Bilateral }\end{array}$ & $\begin{array}{l}\text { Left cochlear } \\
\text { implantation }\end{array}$ & $\begin{array}{l}\text { Good hearing } \\
\text { Regular follow up to April } 2018 \\
\text { CT Scan done thrice (Figure 6) }\end{array}$ \\
\hline 2 & Himanshu & 10.10 .12 & $\begin{array}{l}\text { Bilateral mastoid cavities Dry Epithelized } \\
\text { with profound loss Bilateral }\end{array}$ & $\begin{array}{l}\text { Right Cochlear } \\
\text { Implantation }\end{array}$ & $\begin{array}{l}\text { Did well . Lost to follow up after } \\
3 \text { years }\end{array}$ \\
\hline 3. & RK $22 \mathrm{M}$ & 27.4 .2015 & Do & $\begin{array}{l}\text { Right Cochlear } \\
\text { Implantation }\end{array}$ & $\begin{array}{l}\text { Had partial insertion } 12 \text { electrodes } \\
\text { inserted. Doing well }\end{array}$ \\
\hline
\end{tabular}


Table Continued...

\begin{tabular}{|c|c|c|c|c|c|}
\hline SNo & $\begin{array}{l}\text { Patient's Name } \\
\text { with age }\end{array}$ & DOS & Clinical Presentation & Surgery done & $\begin{array}{l}\text { Outcome with complications } \\
\text { if any }\end{array}$ \\
\hline 4 & SK I8 M & $\begin{array}{l}20.6 .16 \\
7.3 .18\end{array}$ & $\begin{array}{l}\text { Bilateral Mastoid cavities. Diagnosed } \\
\text { as Tubercular Otitis Media after Right } \\
\text { matoidectomy in PGI in } 2013 \text {. } \\
\text { Given ATT for } 9 \text { months. } \\
\text { Any TB focus ruled out by clinical } \\
\text { examination and investigations } \\
\text { (ESR, Montoux test, Chest X ray along } \\
\text { with sputum for AFB) } \\
\text { Had Profound loss at the time of surgery } \\
\text { in PGI . } \\
\text { Left mastoidectomy done outside in } 2012 \text {. }\end{array}$ & $\begin{array}{l}\text { Right Cochlear } \\
\text { Implantation } \\
\text { done after blind } \\
\text { sac closure and } \\
\text { obliteration of } \\
\text { cavity in July } 2016 .\end{array}$ & $\begin{array}{l}\text { Did well for } 21 \text { months } \\
\text { In March } 2018 \text { had extrusion of } \\
\text { electrodes. On re exploration, } \\
\text { next day was found to have canal } \\
\text { cholesteatoma which was } \\
\text { removed Blind sac closure revised } \\
\text { and reimplantation done. Post } \\
\text { operative } x \text { ray Normal }\end{array}$ \\
\hline
\end{tabular}

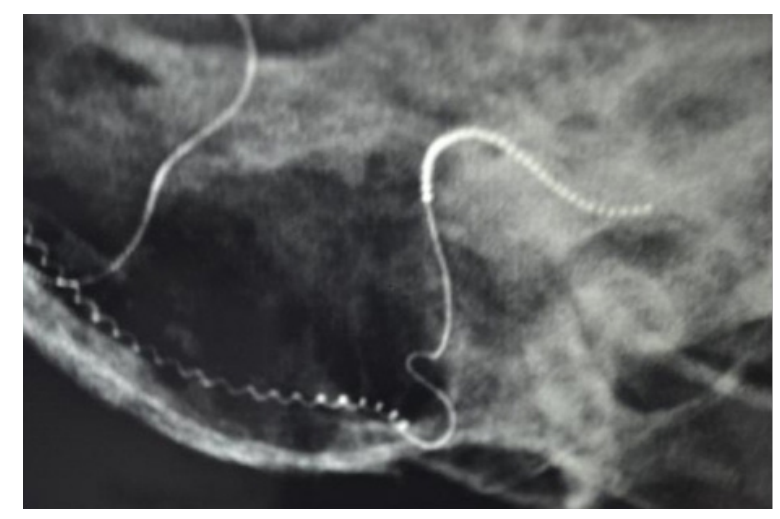

Figure 3 Showing the electrodes out of the cochlea.

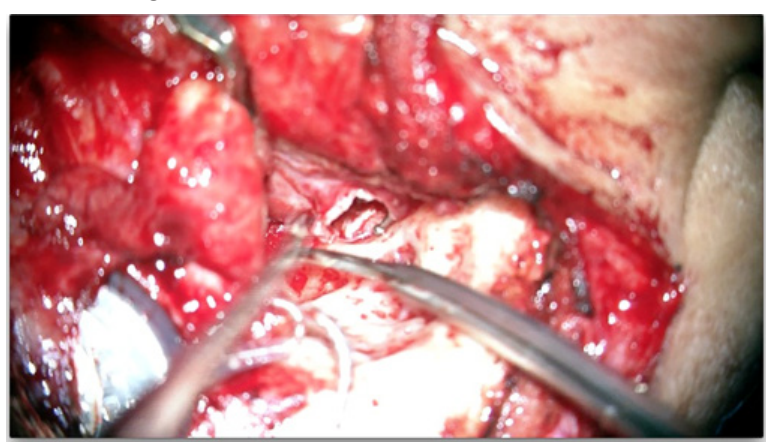

Figure 4 Showing the cholesteatoma in the external auditory canal.

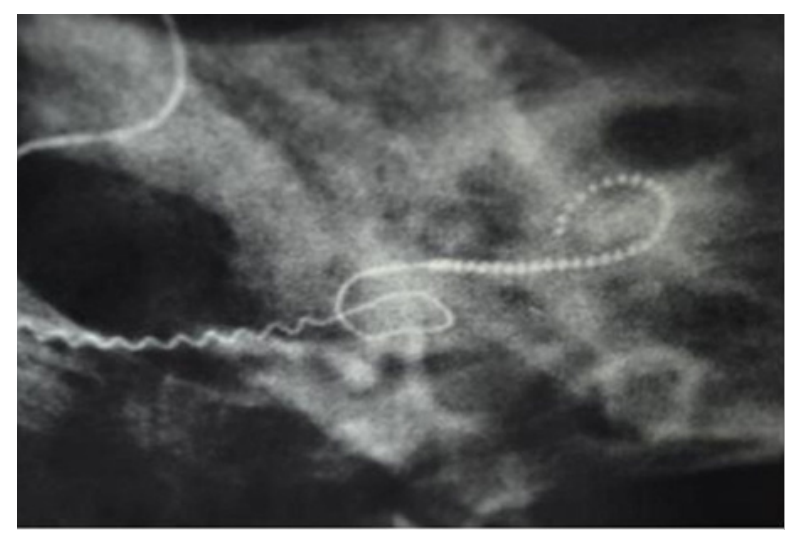

Figure 5 Showing the electrodes in the cochlea.

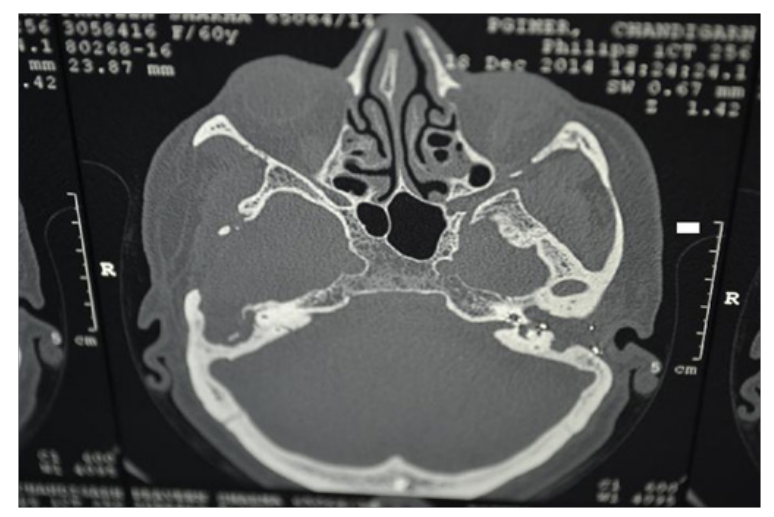

Figure 6 CT scan of patient no I with electrodes in place on the left side 4 years after implantation.

\section{Discussion}

The need for cochlear implantation in radical mastoid cavities merit attention primarily for 2 reasons. First chronic otitis media treated with mastoid surgery may result in profound hearing loss in 3-5 \% cases. ${ }^{5}$ Secondly the prognosis for auditory outcome is good as these patients become progressively deafened post lingually. The question whether to perform cochlear implantation with inactive chronic otitis media with a mastoid cavity continues to remain unanswered. The Surgeons are skeptical for the fear of going through a potentially infected field which communicates intracranially. Cochlear implantation in patients with residual mastoid cavity is complex and presents challenges to the cochlear implant Surgeon. The main question facing the Surgeon is whether to stage the procedure and what material to use for obliteration. In an ear with canal wall down mastoid cavity several authors have described obliteration of mastoid cavity and Cochlear implantation. Schlondorff et al., ${ }^{1}$ suggested use of full thickness flap of post auricular skin which was not accepted as there was possibility of a retro auricular fistula. Gray et al., ${ }^{3}$ reported obliteration of mastoid cavity and Eustachian tube closure and blind sac closure of the external auditory canal. Manrique et al., ${ }^{4}$ reported a technique of single stage surgical procedure of cochlear implantation in radical mastoid cavity. They reported use of cement to stabilize the electrode array. Meyerhoff, Stringer and Roland ${ }^{5}$ also described a technique of revision mastoidectomy with creation of periosteal flap to cover the electrodes and stabilization of electrodes with bone cement. Axon, Mawman, Upile and Ramsden ${ }^{6}$ described a superiorly based temporalis muscle flap for obliteration of 
the cavity. Gray, Ray \& McFerran ${ }^{7}$ described obliteration of mastoid cavities with abdominal fat.

Hamzavi, Baumgartner, Franz \& Plenk ${ }^{8}$ and Donelly, Pyman, Clark ${ }^{9}$ recommended a single stage operation if the mastoid cavity is absolutely dry. Postelmans, Stokroos, Linmans \& Kremer ${ }^{10}$ reported a series of 6 patients with radical mastoid cavity who underwent implantation as a single stage procedure. They did not encounter any post operative complication in any of the 6 patients. El Kashlan, Arts, Telian $^{11}$ and El Kashlan, Telian ${ }^{12}$ opined that cochlear implantation can usually be performed in a single stage in many patients with chronic otitis media. Gray et al., ${ }^{7}$ Axom et al., ${ }^{6}$ and Hamzavi et al., ${ }^{8}$ did not report any complications. Basavraj, Shanks, Sivaji \& Allen ${ }^{13}$ described a series of 3 cases where they obliterated the cavity, closed the ear canal and performed implantation as a single stage procedure

The most important issue in a single stage procedure is the complete removal of the fibro-epithelial lining of the mastoid cavity. The surgeon needs to be certain that no squamous epithelium has been left behind. Donnely et al., ${ }^{9}$ emphasized that it is essential to eradicate all middle ear disease before cochlear implantation. They also suggested that obliteration of the cavity could be necessary. El Kashlan et al., ${ }^{11}$ described a single stage cochlear implantation in chronic otitis media using closure of external auditory canal. The authors did not obliterate the middle ear or the mastoid. The technique was advocated for implantation in patients with a dry tympanic membrane perforation or dry open mastoid cavities. A single stage procedure has advantage of minimizing the need for multiple general anaesthesia and reduces the cost significantly. A single stage cochlear implantation is not advised in patients with active cholesteatoma. These patients undergo removal of cholesteatoma, removal of tympanic membrane remnants along with malleus and incus and blind sac closure of external auditory canal. The middle ear and mastoid are inspected 6 months later, absence of disease is confirmed and then cochlear implantation is performed. Some of the published complications for Cochlear implantation done as a single stage procedure include recurrence of cholesteatoma, and explantation of the electrodes due to flap difficulty. ${ }^{14}$ Donelly et al., ${ }^{9}$ also reported a patient who had recurrence of cholesteatoma after cochlear implantation. Gray et al., ${ }^{3}$ reported a cholesteatoma recurrence which was removed during second operation like in our patient.

Although the number of reports of single stage Cochlear implantation are not too many, the overall results are encouraging. It is imperative that patients have chances of recurrence of cholesteatoma even though they have dry epithelized mastoid cavity. The probability is however very less as there is no active squamous epithelium. Three of the four patients in our series are doing satisfactorily with optimum speech performance. They have a follow up from 24 months to 84 months. In the patient presenting with an extrusion, we had limited options. At that moment, the only option feasible was to re explore the patient. As the infection could spread via the implant to the inner ear and possibility of meningitis, we lost no time in exploring our patient. Our decision to explore and re-implant is also vindicated by the fact that the choelesteatoma was limited only to the external auditory canal. Rest of the mastoid cavity was perfectly normal. In our series we used a vascularised temporo-parietal fascia flap which covered the implant as well as helps in obliterating the cavity. In case of re exploration the surgeon faces less difficulty in lifting the flap from the cavity as the flap is smooth. The well vascularised flap also provides a close and sterile environment for the implant. From our experience in 4 patients, we consider obliteration with this flap is a reliable method to safeguard the implant.
Cochlear implantation thus can be safely undertaken in patients with chronic otitis media. The approach chosen should be individualized based on clinical finings. The risk of developments of cholesteatoma secondary to the blind sac closure of external auditory canal exists in spite of removal of all epithelial remnants. These risks of recurrence of cholesteatoma and possible exposure of the implant should be explained and the patient be appropriately counselled. Thus it is mandatory to keep these patients on regular follow up. Though MRI is a useful way to evaluate recurrent cholesteatoma it may not be feasible in majority of implantees. CT scan thus would be an alternative investigation to detect recurrence. The clinical results with our surgical technique have been excellent in all but one patient. It is the author's opinion that a single stage procedure is recommended in case of patients with chronic otitis media with a dry epithelized cavity.

\section{Conclusions}

Cochlear implantations can be performed as a single stage procedure in patients with a radical mastoid cavity. The surgical team has to ensure complete removal of all squamous epithelium form the mastoid cavity to avoid recurrence of cholesteatoma. A Vascularized temporo parietal fascia flap provides a strong protective layer for the implanted device. A vigilant close follow up is required to exclude development of recurrent cholesteatoma.

\section{Acknowledgments}

None

\section{Conflicts of interest}

No potential conflict of interest and financial interest to disclose by the authors.

\section{Funding}

None.

\section{References}

1. Schlondorff G, Hermes H, Weck L. Cochlear implants Bei patienten ut Radical hole. HNO. 1989;37(10):423-425.

2. Incesulu A, Kolaturk S, Vural M. Cochlear implantation in chronic otitis media. Journal of laryngology, rhinology and otology. 2004;118(1):3-7.

3. Gray RF, Irving RM. Cochlear implants in chronic suppurative otitis media. American Journal of Otology. 1995;16(5):682-686.

4. Manrique M, Cervera Paz FJ, Espinosa IM, et al. Cochlear implantation in radical cavities of mastoidectomy. Laryngoscope. 1996;106(12):15621565

5. Meyerhoff WL, Stringer SP, Roland PS. Rambo procedure : Modification and application. Laryngoscope. 1988;98(7):795-796.

6. Axon PR, Mawman DJ, Upile T, et al. Cochlear implantation in the presence of chronic suppurative otitis media. Journal of laryngology, rhinology and otology. 1997;111(3):228-232.

7. Gray RF, Ray J, McFerran D. Further experience with fat graft obliteration of mastoid cavities for cochlear implants. Journal of laryngology, rhinology and otology. 1996;113(10):881-884.

8. Hamzavi J, Baumgartner W, Franz P, Plenk H. Radical cavities and cochlear implantation. Acta Otolaryngologica. 2001;121(5):607-609.

9. Donelly MJ, Pyman BC, Clark GM. Chronic middle ear disease and Cochlear implantation Annals of Otology, Rhinology and Laryngology. 1995;104(suppl):S406-S408. 
10. Postelmans JT, Stokroos RJ, Linmans JJ, et al. Cochlear implantation in patients with chronic otitis media: 7 year experience in Maastricht. European archives of otorhinolaryngology. 2009;266(8):1159-1165.

11. El Kashlan HK, Arts HA, Telian SA. Cochlear implantation in chronic suppurative otitis media. Otology \& Neurotology. 2002;23(1):53-55.

12. El Kashan HK, Telian SA. Cochlear implantation in the chronically diseased ear. Current Opinion in Otolaryngology Head and Neck Surgery. 2004; 12(5):384-386.
13. Basavraj S, Shanks M, Sivaji N, Allen AA. Cochlear implantation and management of chronic suppurative otits media: single stage procedure? European archives of otorhinolaryngology. 2005;262(10):852-855.

14. Harada T, Ishida K, Endo M, et al. Recurrent extrusion of cochlear implant at an interval of 5 years. Otology \& Neurotology. 2003;24(1):83-85. 